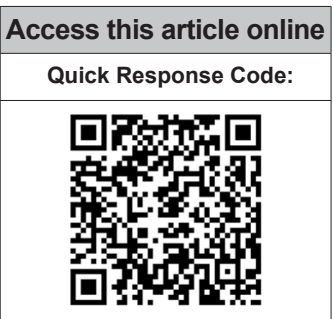

Website:

www.jponline.org

DOI:

10.4103/JLP.JLP_140_17
Departments of Clinical virology, ${ }^{1}$ Hepatobiliary Surgery, ${ }^{2}$ Clinical Research and ${ }^{3}$ Pediatric Hepatology, Institute of Liver and Biliary Sciences, New Delhi, India

Address for correspondence:

Dr. Ekta Gupta, Department of Clinical Virology, Institute of Liver and Biliary Sciences,

D-1, Vasant Kunj, New Delhi - 110 070, India. E-mail: ektagaurisha@ gmail.com

Submission: 02-09-2017 Accepted: 18-12-2017

\title{
Earlier and higher rates of cytomegalovirus infection in pediatric liver transplant recipients as compared to adults: An observational study
}

\author{
Yogita Verma, Ekta Gupta, Niteen Kumar ${ }^{1}$, Nadeem Hasnain, Ajeet Singh Bhadoria ${ }^{2}$, \\ Viniyendra Pamecha', Rajeev Khanna ${ }^{3}$
}

Abstract:

AIM: To study and compare the incidence and time of occurrence of cytomegalovirus (CMV) infection in the posttransplant period in adult and pediatric liver transplant recipients.

MATERIALS AND METHODS: Consecutive live donor liver transplant recipients not on CMV prophylaxis, were prospectively enrolled from March 2012 to September 2015 and followed up for 1 year post transplant to look for CMV infection. For analysis, patients were divided into pediatric (up to 18 years) and adult ( $>18$ years) age groups.

RESULTS: The study population of 146 patients consisted of 132 adult and 14 pediatric patients. Overall CMV infection posttransplant was seen in 54/146 (36.98\%) patients, and 16/54 (29.6\%) patients developed CMV disease. Post-transplant CMV infection rate was significantly higher in pediatric patients(10/14 [71.4\%]) as compared to adults $(44 / 132[33.4 \%])(P=0.004)$. Among adults, CMV infection was seen in $22(50 \%)$ patients in the $1^{\text {st }}$ month, $13(29.5 \%)$ patients in the $2^{\text {nd }}$ month, $5(11.4 \%)$ patients in the $3^{\text {rd }}$ month, $2(4.5 \%)$ patients in the $4^{\text {th }}$ month, and $1(2.3 \%)$ patient each in the $5^{\text {th }}$ and $6^{\text {th }}$ month. However, in pediatric patients, all the patients having CMV infection had it in the $1^{\text {st }}$-month posttransplant $(P=0.003)$. The median time of occurrence of CMV infection was $11.5(7.75-19.00)$ days in pediatric patients versus $30(18.5-54.5)$ days in adult patients $(P=0.001)$.

CONCLUSIONS: The results of this study show a clear difference in the incidence and timeline of posttransplant $\mathrm{CMV}$ infection in pediatric patients as compared to adults.

Key words:

Adults, cytomegalovirus infection, liver transplant, pediatric patients

\section{Introduction}

Cytomegalovirus (CMV) is a herpes virus causing infection in $40 \%-100 \%$ population worldwide. ${ }^{[1,2]}$ Primary infection with $\mathrm{CMV}$ results in latency. CMV infection and disease remain a major health concern after liver transplantation. ${ }^{[3-6]}$ The effects of CMV infection after solid organ transplantation may be serious ranging from tissue-invasive disease to graft rejection and mortality in some cases. ${ }^{[3]}$

This is an open access article distributed under the terms of the Creative Commons Attribution-NonCommercial-ShareAlike 3.0 License, which allows others to remix, tweak, and build upon the work non-commercially, as long as the author is credited and the new creations are licensed under the identical terms.

For reprints contact: reprints@medknow.com
The incidence of CMV infection in the posttransplant period is dependent upon factors such as lack of preexisting CMV-specific humoral/cell-mediated immunity, coinfections (HHV-6/HHV-7), immune deficiencies, immunosuppressive therapy, and prophylactic therapy among others. ${ }^{[6,7]} \mathrm{CMV}$ serostatus of the donor and recipient is the most important predictor of CMV infection and disease posttransplant. ${ }^{[6]}$ Most of the CMV infection and disease in the posttransplant period is a result of CMV reactivation due to the immunosuppression

How to cite this article: Verma Y, Gupta E, Kumar N, Hasnain N, Bhadoria AS, Pamecha V, et al. Earlier and higher rates of cytomegalovirus infection in pediatric liver transplant recipients as compared to adults: An observational study. J Lab Physicians 2018;10:221-5. 
in case of CMV-seropositive transplant recipients. In patients not receiving any prophylactic therapy, most of the clinical effects of CMV occur in the first 3 months posttransplant, and it is estimated that $18 \%-29 \%$ of liver transplant recipients might develop CMV disease within 12 months posttransplant. ${ }^{[3,8]}$ However, in patients receiving prophylactic therapy, $\mathrm{CMV}$ disease occurs 3-6 months after completing the prophylactic therapy and is known as "late-onset CMV disease." ${ }^{[3,9]}$

In the present era where modern surgical techniques and improved immunosuppressive regimens have increased the survival rates to $>90 \%$ in children, more pediatric patients are undergoing liver transplantation than before. ${ }^{[10]}$ In children undergoing solid organ transplant, various pretransplant factors such as age, exposure to infectious agents (CMV / Epstein-Barr virus), immunity, and vaccination status influence the type and severity of infections experienced after transplant. ${ }^{[10,11]}$ Therefore, to provide better care to the pediatric liver transplant recipients, it is important to understand the kinetics of posttransplant CMV infection in these patients as compared to adults. The objective of this study was to study and compare the incidence and time of occurrence of CMV infection in the posttransplant period in adult and pediatric liver transplant recipients.

\section{Materials and Methods}

\section{Study design}

This prospective study was conducted in our center on liver transplant recipients. Consecutive patients undergoing live donor liver transplant at the institute were enrolled from March 2012 to September 2015 and followed up for 12 months posttransplant. Patients who were HIV coinfected, unwilling to give consent, received cadaveric liver transplant or another organ cotransplant along with liver were excluded from the study. Patients who died during the follow-up period were excluded from the analysis. Patients were divided into adults ( $>18$ years) and pediatric (up to 18 years) for the purpose of analysis.

CMV infection and disease were diagnosed and defined as per the recommendations. ${ }^{[12]} \mathrm{CMV}$-DNA positivity in the blood (DNAemia) was considered as the evidence of CMV infection. CMV disease, i.e., CMV infection with attributable symptoms, was further categorized as CMV syndrome (fever, malaise, leukopenia, and/or thrombocytopenia) and CMV tissue-invasive disease (detection of CMV in the tissue specimen).

\section{Immunosuppression protocol}

All patients received triple-regimen immunosuppression (tacrolimus + mycophenolate mofetil + steroid). The trough level of tacrolimus was maintained at
5-10 $\mathrm{ng} / \mathrm{mL}$. Steroids were tapered in majority by the end of 3 months.

\section{Preemptive therapy}

None of the liver transplant recipients was on anti-CMV prophylaxis. Patients were clinically examined for signs and symptoms of CMV infection every month. Patients were given preemptive treatment if the CMV viral load was $>500$ copies $/ \mathrm{ml}$ (significant viremia), regardless of clinical manifestations as per the Institution Protocol. The patients received preemptive therapy consisting of intravenous ganciclovir ( $5 \mathrm{mg} / \mathrm{kg}$, 12 hourly) or oral valganciclovir (900 mg twice daily) until the patient became negative for CMV infection. Therapy was stopped once two consecutive samples taken 2 weeks apart were negative for CMV DNA.

\section{Sample collection}

Pretransplant blood samples were collected in ethylenediaminetetraacetic acid vials from all transplant recipients and their respective donors for CMV IgG antibody detection and polymerase chain reaction (PCR) for CMV-DNA detection. Plasma levels of CMV-DNA were measured every week up to 1 month, every fortnight up to 2 months, and monthly up to 1-year posttransplant.

\section{Cytomegalovirus IgG detection}

Determination of IgG antibodies to CMV in plasma was done by the Architect CMV-IgG assay (Abbott Laboratories, Chicago, IL, USA) which is a chemiluminescent microparticle immunoassay as per the manufacturer's instructions. The cutoff values were calculated based on each individual run to determine each sample as reactive or nonreactive.

\section{Cytomegalovirus real-time polymerase chain reaction}

Plasma was separated from the blood collected from the patients, and viral DNA was extracted using High Pure Viral Nucleic Acid Kit (Roche Diagnostics $\mathrm{GmbH}$, Roche Applied Science, Germany) as per the manufacturer's instructions. Quantitative Real-Time PCR for CMV was performed in plasma samples using the LightCycler ${ }^{\circledR} 480$ II Real-Time PCR System (Roche Life Science, USA). This assay targets viral glycoprotein gene gpB (UL 55), $226 \mathrm{bp}$ in size using Light DNA master hybridization probe. Results were expressed as copies of virus/ml plasma. The linear range of the test is $102-106$ copies/mL with the lower limit of detection being 10 copies $/ \mathrm{mL}$.

\section{Statistical analysis}

Quantitative variables were expressed as median with range, and qualitative variables were expressed as percentage. Chi-square test was used to compare the data in two groups. A " $P$ " < 0.05 was considered statistically 
significant. Statistical analysis was done using SPSS version 20 (SPSS Inc., Chicago, IL, USA).

\section{Ethical considerations}

The study design and methodology were approved by the Institutional Ethics Committee.

\section{Results}

Baseline characteristics of the study population A total of 163 patients were screened. Nine patients were excluded from the study as they did not fulfill the inclusion criteria. Eight patients died during the follow-up period and hence excluded from the analysis. The final analysis included 146 patients [Figure 1] which consisted of $114(78 \%)$ males and $32(22 \%)$ females. There were 132 adult and 14 pediatric patients in the study population. The CMV serostatus in all 14 pediatric patients was $\mathrm{D}+\mathrm{R}+(\mathrm{D}=$ donor, $\mathrm{R}=$ recipient $)$, whereas among adults, 128 were $\mathrm{D}+\mathrm{R}+$ and 4 were $\mathrm{D}-\mathrm{R}+$ [Table 1 ].

The most common indication for liver transplant was cryptogenic liver disease, followed by alcoholic liver disease, acute liver failure of unknown etiology, and chronic hepatitis B and C [Table 2].

\section{Cytomegalovirus infection}

CMV-DNA was not detected by PCR in any patient in the pretransplant blood samples. Overall CMV infection was seen in 54/146 (36.98\%) patients in the posttransplant period. Posttransplant CMV infection rate was significantly higher in pediatric 10/14 (71.4\%) as compared to adult $44 / 132(33.4 \%)$ patients $(P=0.004)$. Significant viremia (CMV viral load of $>500$ copies $/ \mathrm{ml}$ ) was seen in $32 / 44$ adult and $7 / 10$ pediatric patients showing CMV infection.

Timeline of CMV infection posttransplant is represented in Table 3. Majority of patients having CMV infection had it in the first 3 months posttransplant. Among adults, a total of 44 patients had CMV infection. Out of these, CMV

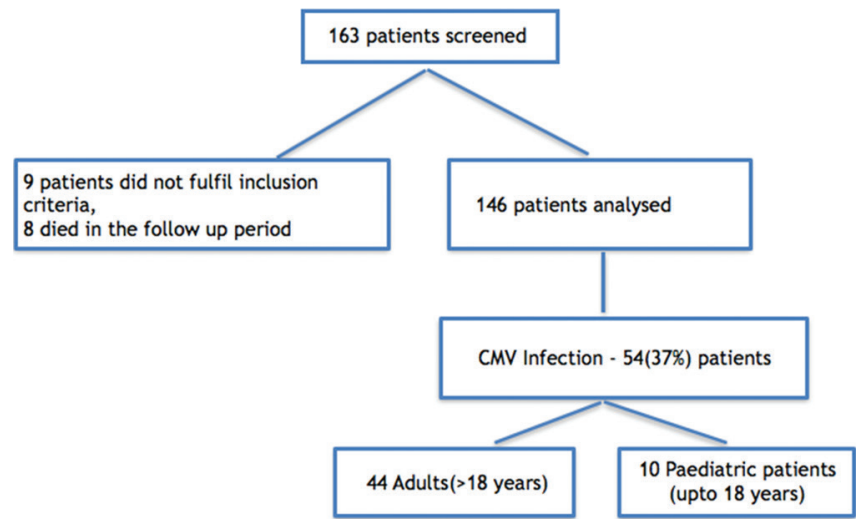

Figure 1: Flow diagram depicting the study population and number of patients with cytomegalovirus infection posttransplant infection was seen in $22(50 \%)$ patients in the $1^{\text {st }}$ month, $13(29.5 \%)$ patients in the $2^{\text {nd }}$ month, $5(11.4 \%)$ patients in the $3^{\text {rd }}$ month, $2(4.5 \%)$ patients in the $4^{\text {th }}$ month, and $1(2.3 \%)$ patient each in the $5^{\text {th }}$ and $6^{\text {th }}$ month. No CMV infection was seen in any patient in the follow-up duration of $7^{\text {th }}-12^{\text {th }}$ month. In the pediatric age group, all 10 patients had CMV infection in the $1^{\text {st }}$-month posttransplant and none after that. This difference in the timeline of posttransplant CMV infection between adult and pediatric liver transplant recipients was found to be statistically significant $(P=0.003)$ [Table 3].

CMV infection was observed significantly earlier in pediatric patients as compared to adults. The median time of occurrence of CMV infection was 11.5 (7.75-19.00) days in pediatric patients versus 30 (18.5-54.5) days in adult patients $(P=0.001)$. The median viral load of CMV in adult patients was $1.49 \times 10^{3}\left(3.90 \times 10^{2}-8.67 \times 10^{3}\right)$ copies $/ \mathrm{ml}$ as compared to $4.81 \times 10^{3}\left(3.45 \times 10^{2}-10.77 \times 10^{3}\right)$ copies $/ \mathrm{ml}$ in pediatric

Table 1: Baseline characteristics of the study population

\begin{tabular}{lcc}
\hline & $\begin{array}{c}\text { Adults } \\
>18 \text { years }(\%)\end{array}$ & $\begin{array}{c}\text { Pediatric patients } \\
\text { Up to } 18 \text { years (\%) }\end{array}$ \\
\hline Number of subjects & $132(90.4)$ & $14(9.6)$ \\
Mean age (years) & $42.9 \pm 11.09$ & $6.8 \pm 3.29$ \\
Males & $104(78.78)$ & $10(71.42)$ \\
Females & $32(21.22)$ & $4(28.58)$ \\
Pretransplant CMV serostatus & & \\
of D/R & & \\
D+R+ & $128(96.96)$ & $14(100)$ \\
D-R+ & $4(3.04)$ & Nil $(0)$ \\
D+R- & Nil (0) & Nil $(0)$ \\
D-R- & Nil (0) & Nil (0) \\
\hline
\end{tabular}

$\mathrm{D}=$ Donor, $\mathrm{R}=$ Recipient, $\mathrm{CMV}=$ Cytomegalovirus

Table 2: End-stage liver disease in adult and pediatric live donor liver transplant recipients

\begin{tabular}{lcc}
\hline Cause & $\begin{array}{c}\text { Adults } \\
(n=132), n(\%)\end{array}$ & $\begin{array}{c}\text { Pediatric } \\
(n=14), n(\%)\end{array}$ \\
\hline Cryptogenic & $47(35.61)$ & $1(7.14)$ \\
ALD & $33(25)$ & Nil (0) \\
ALF & $16(12.12)$ & $9(64.28)$ \\
CLD-B & $13(9.9)$ & Nil (0) \\
CLD-C & $6(4.55)$ & Nil (0) \\
Primary biliary cirrhosis & $5(3.8)$ & Nil (0) \\
CLD-NASH & $2(1.5)$ & Nil (0) \\
Secondary biliary cirrhosis & $2(1.5)$ & Nil (0) \\
Wilson's disease & $2(1.5)$ & Nil (0) \\
Drug-induced (ATT) & $2(1.5)$ & Nil (0) \\
ACLF & $2(1.5)$ & $2(14.29)$ \\
Autoimmune hepatitis & $1(0.76)$ & Nil (0) \\
Biliary atresia & $1(0.76)$ & $2(14.29)$ \\
\hline ALF = Acute liver failure, CLD = Chronic liver disease, CLD-B = CLD due \\
to hepatitis B virus, CLD-C = CLD due to hepatitis C virus, ALD = Alcoholic \\
liver disease, NASH = Nonalcoholic steatohepatitis, ATT = Antituberculosis \\
treatment, ACLF = Acute on chronic liver failure
\end{tabular}


patients. However, the difference was statistically insignificant [Figure 2].

CMV disease was seen in 16/54 (29.6\%) patients (fever, malaise, abnormal leukocyte counts/thrombocytopenia) and no patient developed tissue-invasive disease. A total of $2 / 10(20 \%)$ pediatric patients and $14 / 44(31.8 \%)$ adults developed CMV disease. The median time of occurrence of CMV disease was 32 (8.4-76.5) days. The median viral load in patients who developed CMV disease was $1.74 \times 10^{3}\left(1.96 \times 10^{2}-5.3 \times 10^{5}\right)$ copies $/ \mathrm{ml}$ as compared to $1.52 \times 10^{3}\left(1.18 \times 10^{2}-6.8 \times 10^{4}\right)$ copies $/ \mathrm{ml}$ in patients with only CMV infection. This difference was statistically insignificant. All CMV infections were successfully treated with ganciclovir/valganciclovir as part of preemptive therapy as per the institute's protocol mentioned above. No difference in outcome of patients with CMV infection and CMV disease was found in this study.

\section{Discussion}

The rates of CMV infection and disease in the posttransplant period vary with the serostatus of

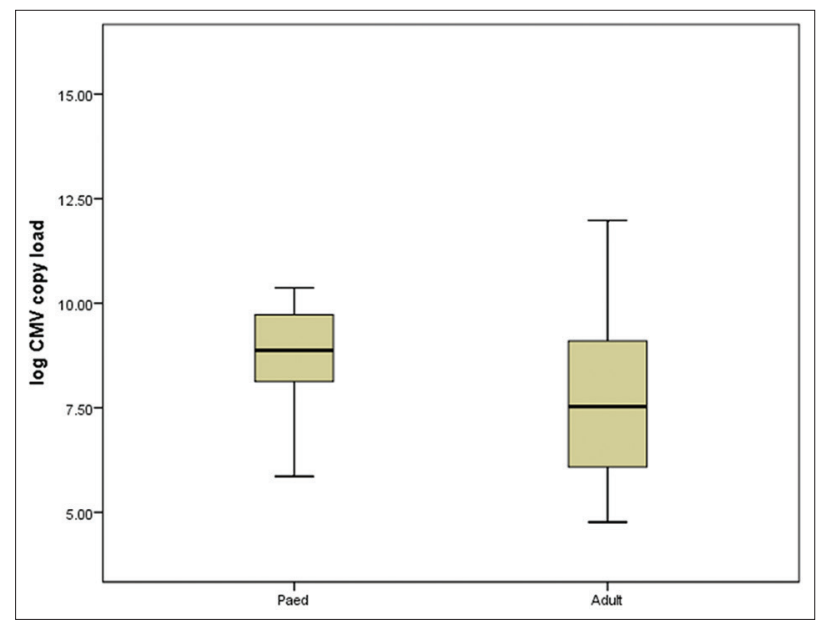

Figure 2: Box-plot representing median cytomegalovirus load (after log transformation) in adult and pediatric liver transplant recipients $(P=0.54)$ donor and recipient and the administration of antiviral prophylaxis along with other factors. ${ }^{[3,6,8,13,14]}$ This study dealt only with CMV-seropositive transplant recipients and none of them received antiviral prophylaxis. The overall rates of CMV infection and disease were found to be $36.9 \%$ and $10.95 \%$, respectively. It has been estimated that in the absence of antiviral prophylaxis, the rate of CMV disease in the $1^{\text {st }}$-year posttransplant is between $8 \%$ and $19 \%$ in CMV-seropositive liver transplant recipients. ${ }^{[3,8]}$ The results of the present study are concordant with the same.

Overall, highest rate of CMV infection was observed in the first 3 months with more than half of the infections occurring in the $1^{\text {st }}$-month posttransplant. The timeline is highly dependent on factors such as levels of immunosuppression and preventive strategy adopted. . $^{[8,9,15,16]}$ Reports have appeared in literature in recent times stating that majority of the CMV infections take place in the first 3-month posttransplant. ${ }^{[3,6]}$ However, there is an interesting trend to be noticed in the timeline of CMV infection in the present study as all the CMV infections in children and majority of infections in adults were seen in the $1^{\text {st }}$-month posttransplant. The pretransplant $\mathrm{CMV}$-seropositive status of the transplant recipients and the absence of antiviral prophylaxis might have led to this finding.

If the CMV infection rates in adults and pediatric population are looked at separately, a significantly higher rate of CMV infection (71.4\%) was observed in pediatric patients as compared to adults $(33.4 \%)(P=0.004)$. The median time to $\mathrm{CMV}$ infection was also significantly lesser in pediatric patients ( 11.5 days vs 30 days) $(P=0.001)$. There are no recent studies which compare the incidence of CMV infection in adult and pediatric liver transplant recipients. However, Breinig et al. ${ }^{[17]}$ in 1987 reported high rates of CMV reactivation in children (88\%) in the USA, which were similar to those in adults. Preventive and immunosuppressive strategies have evolved a lot since then and have reduced the incidence of CMV infection

Table 3: Comparison of cytomegalovirus infection between adult and pediatric liver transplant recipients

\begin{tabular}{|c|c|c|c|}
\hline Parameter & Adult patients ( $n=132), n(\%)$ & Pediatric patients $(n=14), n(\%)$ & $P$ \\
\hline CMV infection & 44/132 (33.4) & $10 / 14(71.4)$ & 0.004 \\
\hline$<500$ copies $/ \mathrm{ml}$ & 12 & 3 & \\
\hline$>500$ copies $/ \mathrm{ml}$ & 32 & 7 & \\
\hline Median viral load (copies/ml) (range) & $1.49 \times 10^{3}\left(3.90 \times 10^{2}-8.67 \times 10^{3}\right)$ & $4.81 \times 10^{3}\left(3.45 \times 10^{2}-10.77 \times 10^{3}\right)$ & 0.54 \\
\hline $1^{\text {st }}$ month & $22(50)$ & $10(100)$ & 0.003 \\
\hline $2^{\text {nd }}$ month & $13(29.5)$ & Nil & \\
\hline $3^{\text {rd }}$ month & $5(11.4)$ & Nil & \\
\hline $4^{\text {th }}$ month & $2(4.5)$ & Nil & \\
\hline $5^{\text {th }}$ and 6th month & 1 (2.3) each & Nil & \\
\hline $7^{\text {th }}-12^{\text {th }}$ month & Nil & Nil & \\
\hline Median days to $\mathrm{CMV}$ infection & $30(18.5-54.5)$ & $11.5(7.75-19.00)$ & 0.001 \\
\hline
\end{tabular}

$\mathrm{CMV}=$ Cytomegalovirus 
and disease. In a recent study from London, the authors have reported CMV infection rate of $66.7 \%$ in D + R + pediatric liver transplant recipients, ${ }^{[18]}$ which is similar to the results of this study.

In our center, we mostly deal with CMV- seropositive patients and preemptive-preventive strategy is being followed in accordance with the guidelines by Kotton et al. ${ }^{[7]}$ There are no clear guidelines stating the time when the monitoring should start posttransplant. ${ }^{[7,19]}$ The results of the study suggest that it should be immediately after transplant, especially in children to avoid missing significant yet asymptomatic CMV infection. The small study population of the children is however a limiting factor in this study and the findings need to be established by conducting a similar study on a larger scale in seropositive population.

\section{Future directions}

The dynamics of CMV reactivation seem to be different in the pediatric population, and therefore separate guidelines might be needed to cater to such patients. Long-term prospective studies and randomized control trials need to be taken up in India to fine tune the existing preventive strategies.

\section{Conclusions}

The results of this study show a clear difference in the incidence and timeline of posttransplant CMV infection in pediatric patients as compared to adults. Larger studies should be done to establish this observation and decide upon the preventive strategies to be adopted (antiviral prophylaxis/preemptive therapy) in pediatric liver transplant recipients.

\section{Acknowledgment}

We would like to thank Mr. Gaurav Singh for his technical support.

\section{Financial support and sponsorship}

Financial support for the study was provided by Indian Council of Medical Research. Grant number VIR/38/2011/ECD-1.

\section{Conflicts of interest}

There are no conflicts of interest.

\section{References}

1. Krech U. Complement-fixing antibodies against cytomegalovirus in different parts of the world. Bull World Health Organ 1973;49:103-6.

2. Kothari A, Ramachandran VG, Gupta P, Singh B, Talwar V. Seroprevalence of cytomegalovirus among voluntary blood donors in Delhi, India. J Health Popul Nutr 2002;20:348-51.

3. Razonable RR. Cytomegalovirus infection after liver transplantation: Current concepts and challenges. World J Gastroenterol 2008;14:4849-60.

4. Harvala H, Stewart C, Muller K, Burns S, Marson L, MacGilchrist A et al. High risk of cytomegalovirus infection following solid organ transplantation despite prophylactic therapy. J Med Virol 2013;85:893-8.

5. Weigand K, Schnitzler P, Schmidt J, Chahoud F, Gotthardt D, Schemmer $\mathrm{P}$, et al. Cytomegalovirus infection after liver transplantation incidence, risks, and benefits of prophylaxis. Transplant Proc 2010;42:2634-41.

6. Marcelin JR, Beam E, Razonable RR. Cytomegalovirus infection in liver transplant recipients: Updates on clinical management. World J Gastroenterol 2014;20:10658-67.

7. Kotton CN, Kumar D, Caliendo AM, Asberg A, Chou S, Danziger-Isakov L, et al. Updated international consensus guidelines on the management of cytomegalovirus in solid-organ transplantation. Transplantation 2013;96:333-60.

8. Lee SO, Razonable RR. Current concepts on cytomegalovirus infection after liver transplantation. World J Hepatol 2010;2:325-36.

9. Arthurs SK, Eid AJ, Pedersen RA, Dierkhising RA, Kremers WK, Patel R, et al. Delayed-onset primary cytomegalovirus disease after liver transplantation. Liver Transpl 2007;13:1703-9.

10. Halasa N, Green M. Immunizations and infectious diseases in pediatric liver transplantation. Liver Transpl 2008;14:1389-99.

11. Green M, Michaels MG. Infections in pediatric solid organ transplant recipients. J Pediatric Infect Dis Soc 2012;1:144-51.

12. Ljungman P, Griffiths P, Paya C. Definitions of cytomegalovirus infection and disease in transplant recipients. Clin Infect Dis 2002;34:1094-7.

13. Bruminhent J, Razonable RR. Management of cytomegalovirus infection and disease in liver transplant recipients. World J Hepatol 2014;6:370-83.

14. Rubin RH. Cytomegalovirus in solid organ transplantation. Transpl Infect Dis 2001;3 Suppl 2:1-5.

15. Kalil AC, Levitsky J, Lyden E, Stoner J, Freifeld AG. Meta-analysis: The efficacy of strategies to prevent organ disease by cytomegalovirus in solid organ transplant recipients. Ann Intern Med 2005;143:870-80.

16. Azevedo LS, Pierrotti LC, Abdala E, Costa SF, Strabelli TM, Campos SV, et al. Cytomegalovirus infection in transplant recipients. Clinics (Sao Paulo) 2015;70:515-23.

17. Breinig MK, Zitelli B, Starzl TE, Ho M. Epstein-barr virus, cytomegalovirus, and other viral infections in children after liver transplantation. J Infect Dis 1987;156:273-9.

18. Verma A, Palaniswamy K, Cremonini G, Heaton N, Dhawan A. Late cytomegalovirus infection in children: High incidence of allograft rejection and hepatitis in donor negative and seropositive liver transplant recipients. Pediatr Transplant 2017;21:e12879. Available from: https://doi.org/10.1111/petr.12879. [Last accessed on 2017 Nov 11].

19. Kotton CN, Kumar D, Caliendo AM, Asberg A, Chou S, Snydman DR, et al. International consensus guidelines on the management of cytomegalovirus in solid organ transplantation. Transplantation 2010;89:779-95. 